\title{
Reflections on the Structure, Mathematics and Aesthetics of Shell Structures
}

\author{
Samar Malek ${ }^{1}$ Chris J. K. Williams ${ }^{2}$
}

Published online: 26 September 2017

(c) Kim Williams Books, Turin 2017

\begin{abstract}
Guest Editors Samar Malek and Chris Williams provide an overview of the aesthetic properties of shell and tension structures, drawing on classical arguments about the relationship between nature, mathematics and architecture. The letter concludes with an introduction to the papers in NNJ 19(3).
\end{abstract}

Keywords Shell structures · Gridshells · Structures · Structural engineering · Membranes

Shell structures provide a simplicity and elegance in their aesthetics. There is something to be said about the appeal of the uninterrupted span, the smoothness of the curvature, the lightness of the structure, and the fluidity of the lines. But why are shell structures inherently beautiful?

In our opinion, the aesthetically pleasing attributes of shells boil down to their structural efficiency. Structural efficiency means that the amount of material needed to support the loads is minimized. For shells, that small amount of material is translated into the thinness of the structure. How that structure is allowed to be thin has to do with its curvature. The curvature increases the 'geometric stiffness' of the shell, but is also derived from the flow of forces. The shape of the shell is in reaction

Samar Malek

malek@usna.edu

Chris J. K. Williams

C.J.K.Williams@bath.ac.uk

1 Department of Mechanical Engineering, United States Naval Academy, 590 Holloway Road, Annapolis, MD 21401, USA

2 Department of Architecture and Civil Engineering, University of Bath, Claverton Down, Bath BA2 7AY, UK 
to the loads and environmental conditions. The shape is intuitive, and natural. We arrive at that form because, as in nature, shell structures in the built environment obey the same physical laws and constraints. Allow us to explain the structural mechanics and mathematics that create these attributes (thinness, curvature and shape). This will also provide the readers with a background to the other papers presented in this special issue of the Nexus Network Journal.

There are two ways structures can carry loads: by axial action or by bending action. All structural action can be simplified into tension and compression forces. When a structure behaves purely in tension (like the cable of a suspension bridge) or purely in compression (like the arch of a bridge), the action is said to be axial and all the material of the cross-section is needed to support the load; no material is wasted and it is an efficient structure. When a structure has tension and compression forces acting simultaneously in the same member (as in the beam supporting a floor), the resulting action is bending. Because most beams are uniform in their cross-section, a significant amount of material is wasted. Thus, it is more efficient for a structure to behave axially than by bending. It is also much easier to bend a surface than it is to stretch it and therefore shells are designed to primarily resist loads through axial action, which in the case of shells is known as membrane action. Bending action is still needed for compression shells that must also resist buckling (Timoshenko 1961). Corrugations increase the bending stiffness of a shell or plate in one direction by using membrane action, but in so doing reduce the membrane stiffness in the orthogonal direction (Fig. 1 from Malek 2017).

The geometry of a shell structure is described by a curved surface; the study of curved lines and surfaces is classical differential geometry (Struik 1961). The word "classical" is used because it applies here to three dimensions, but differential geometry is also applied to higher dimensions, in particular the four dimensions of curved space-time in the general theory of relativity (Dirac 1975).

There is a very close relationship between geometry and structural action. This has been known since the eighteenth and nineteenth centuries through the work of

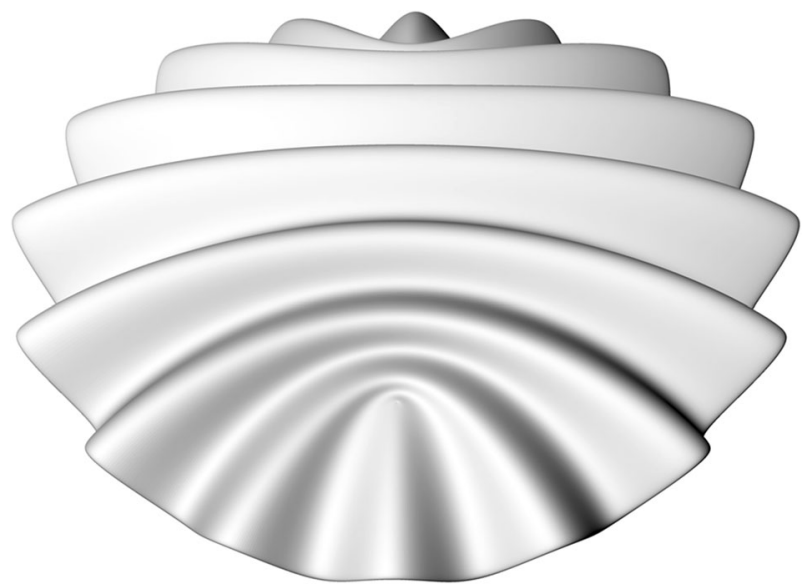

Fig. 1 Computer model of corrugated shell described in Malek (2017) 
Varignon (1725) and Maxwell (1870), amongst others. In the membrane theory of shells, the load is balanced by the membrane stress multiplied by the curvature, and thus the shape of the shell affects its structural action. The mathematics of the geometry and structural action of shell structures can be combined using the tensor notation (Naghdi 1962; Green and Zerna 1968; Koiter 1970).

There is no doubt that the mathematics of differential geometry and shell structures is "beautiful", but whether the beautiful mathematics leads to beautiful structures is an impossible question to answer. To give particular shapes such as the catenary or the hyperbolic paraboloid a transcendental importance is fatuous and shows the lack of a full understanding of all the factors which influence the performance of a shell structure.

As engineers and specialist in shell structures, we know the technical side of shells and could write pages on their mathematics and mechanics. However, we also want to be able to talk rationally about their aesthetics, which should not be only left to the architects or philosophers. In this quest to talk about aesthetics, structure and mathematics in shells, we look to architects, engineers, scientists, philosophers and others who have commented on these topics.

In 1910 the architect Adolf Loos starts his essay Architecture with these words:

May I lead you to the shores of a mountain lake? The sky is blue, the water green and everything is profoundly peaceful. Mountains and clouds are reflected in the lake, and so are houses, farm-yards and chapels. These do not see man made, but more like the product of God's workshop, like the mountains and the trees, the clouds and the blue sky. And everything breathes beauty and tranquility.

Ah, what is that? A false note in this harmony. Like an unwelcome scream. In the centre, beneath the peasants' homes which were created not by them but by God, stands a villa. Is it the product of a good or a bad architect? I do not know. I only know that peace, tranquility and beauty are no more.

For there are no good or bad architects in the eyes of God. Near to his throne, all architects are equal. In the towns, in the realms of Belial, there you will find fine distinctions, as you would expect among the depraved. And therefore I ask: how is it that every architect, however good or bad, violates the lake?

The peasant does not do this. Nor the engineer who builds a railway to the shores of the lake or draws deep furrows through the clear mirror-like surface, with his ship. They create in a different way (Loos 1975: 41).

Loos makes three points: (1) nature is beautiful; (2) structures that serve a function do not disrupt that beauty; (3) when a conscious effort is made to make something beautiful it ceases to be beautiful. Engineers might smirk at the reference to architects, but the fact is that there is no real distinction between the engineer and the architect in the design of shell structures. When one speaks of designers such as Eladio Dieste, Félix Candela (Fig. 2), Santiago Calatrava and Frei Otto, one is never sure whether to describe them as engineers or architects. 


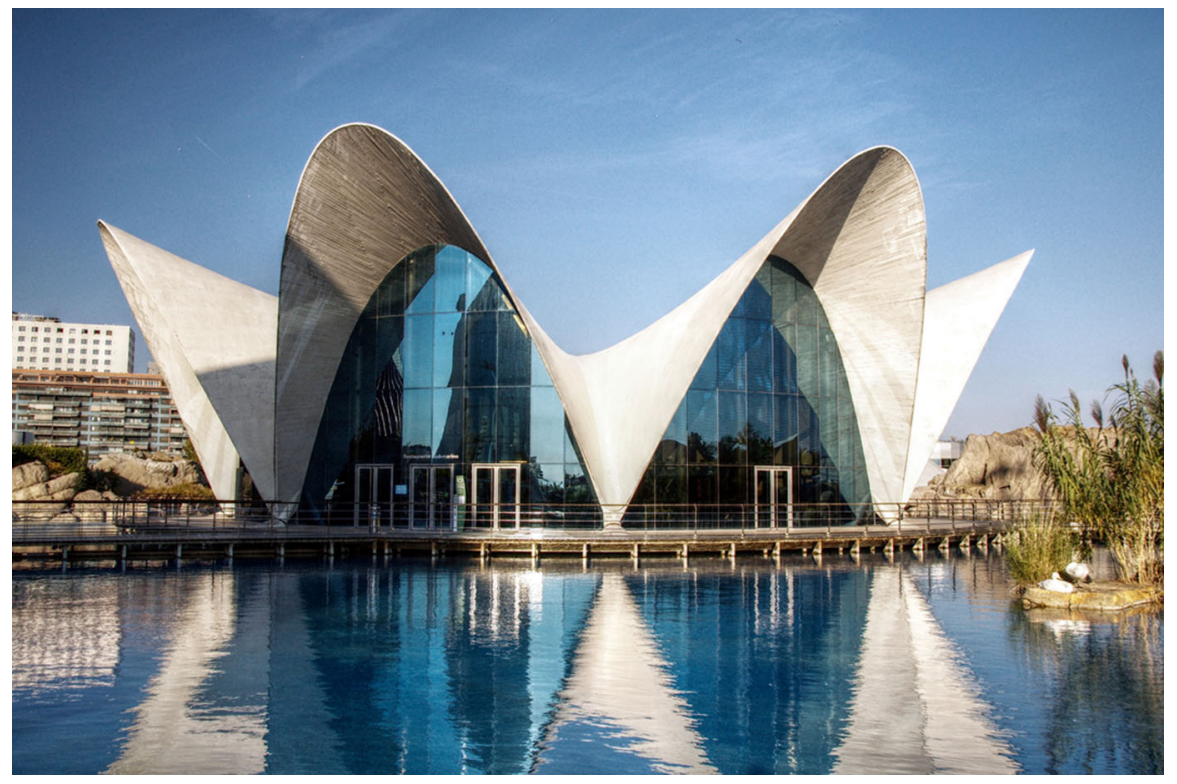

Fig. 2 Oceanografic designed by Félix Candela, City of Arts and Sciences, Valencia, Spain. Photo: Felipe Gabalón, Wikimedia create commons license

Nevertheless, those with a mathematical or academic way of thinking, whether they are engineers or architects, would like to be able to talk rationally about aesthetics. Roger Scruton (2011) suggests that we might look for 'A Bit of Help from Wittgenstein', a friend of Adolf Loos who studied aeronautical engineering before turning to philosophy. Wittgenstein, in the Tractatus Logico-Philosophicus (1922), frames five statements that are particularly relevant.

4.003. Most propositions and questions, that have been written about philosophical matters, are not false, but senseless. We cannot, therefore, answer questions of this kind at all, but only state their senselessness. Most questions and propositions of the philosophers result from the fact that we do not understand the logic of our language.

(They are of the same kind as the question whether the Good is more or less identical than the Beautiful.)

And so it is not to be wondered at that the deepest problems are really no problems.

6.41. The sense of the world must lie outside the world. In the world everything is as it is and happens as it does happen. In it there is no valueand if there were, it would be of no value.

If there is a value which is of value, it must lie outside all happening and being-so. For all happening and being-so is accidental.

What makes it non-accidental cannot lie in the world, for otherwise this would again be accidental.

It must lie outside the world. 
6.42. Hence also there can be no ethical propositions.

Propositions cannot express anything higher.

6.421. It is clear that ethics cannot be expressed.

Ethics is transcendental.

(Ethics and aesthetics are one.)

7. Whereof one cannot speak, thereof one must be silent $(1922: 45,105,108)$.

These statements perhaps suggest that we should be silent and stop here, but we should not give up so easily. There is value in us talking about aesthetics. Umberto Eco, a writer, linguist and philosopher, and Gilles Deleuze, a philosopher, are among those who have discussed beauty, nature, architecture and mathematics and made contributions.

Eco's On Beauty (2010) is largely about human beauty, but contains interesting observations on buildings, including reflections on the writings of Thomas Aquinas (see also Eco 1988). Deleuze's The Fold (1993) is especially relevant, given its focus mathematics and curvature. However, even though Deleuze was clearly inspired by mathematics, he had no real understanding of the work of mathematicians like Gauss, who laid the foundations for the geometry of surfaces, which is central to the theory of shells (Naghdi 1962; Green and Zerna 1968; Koiter 1970). This criticism is perhaps a bit unfair, since there is no doubt that Deleuze's work has a poetic quality. Despite the admonishments of Wittgenstein the Affaire Sokal (Sokal 1996; Bricmont and Sokal 1998), it is still worth talking about some things, even when one cannot talk precisely.

While we cannot talk precisely about aesthetics in a philosophical or artistic sense, let us go back and reassess shell structures from an engineering standpoint. If nature is beautiful, then let us discuss the theories on how nature came to be and how they relate to the design of shell structures.

J. Bell Pettigrew (1834-1908) believed in a Higher Being controlling design. In the introduction to his Design in Nature he wrote:

The magnitude of the creative acts and the enormous antiquity of the universe conclusively point to the eternal nature of the Being by Whom, and through Whom, everything exists. His presence in matter, force, life, and intellectual manifestations of all kinds can scarcely be gainsaid if the reasoning faculties be allowed free play and the dictates of conscience followed (Pettigrew 1908: xxviii).

We are not suggesting the existence of a Higher Being, but when Pettigrew argues that nature came to be by a deliberate, intelligent design process- that it was consciously done-this recalls the deliberate design of the architect and engineer. If the designer understands the mathematics and physics of the structure then he or she is using 'intelligent design', which we might call 'sentient engineering design'.

It is difficult nowadays to argue for intelligent design in nature and to suggest that beauty in nature is the result of some conscious design process. Even though the concept of some form of evolution dates back to classical antiquity, it was Charles Darwin's (1809-1882) concept of natural selection in living nature which finally made it impossible for most people to believe in intelligent design, although it is 
interesting that Pettigrew was a generation younger than Darwin. In the Origin of Species Darwin wrote

Again, it may be asked, how is it that varieties, which I have called incipient species, become ultimately converted into good and distinct species, which in most cases obviously differ from each other far more than do the varieties of the same species? How do those groups of species, which constitute what are called distinct genera, and which differ from each other more than do the species of the same genus, arise? All these results, as we shall more fully see in the next chapter, follow inevitably from the struggle for life. Owing to this struggle for life, any variation, however slight and from whatever cause proceeding, if it be in any degree profitable to an individual of any species, in its infinitely complex relations to other organic beings and to external nature, will tend to the preservation of that individual, and will generally be inherited by its offspring. The offspring, also, will thus have a better chance of surviving, for, of the many individuals of any species which are periodically born, but a small number can survive. I have called this principle, by which each slight variation, if useful, is preserved, by the term of Natural Selection, in order to mark its relation to man's power of selection. We have seen that man by selection can certainly produce great results, and can adapt organic beings to his own uses, through the accumulation of slight but useful variations, given to him by the hand of Nature. But Natural Selection, as we shall hereafter see, is a power incessantly ready for action, and is as immeasurably superior to man's feeble efforts, as the works of Nature are to those of Art (Darwin 1859: 61).

Interestingly, many of today's computational methods in design employ genetic algorithms to reach an optimized solution.

In his book On Growth and Form (1917), biologist, mathematician and classics scholar D'Arcy Thompson (1860-1948) detailed how the physical laws of nature affected the structure of living organisms: their shapes morphed to maintain their structural integrity against the natural elements. He is said to have influenced countless thinkers, artists and architects, including Alan Turing, Claude LéviStrauss, Henry Moore, Barbara Hepworth, Salvador Dalí, Jackson Pollock, Mies van der Rohe and Le Corbusier. Frei Otto frequently referred to Thompson's work in his lectures, especially those related to "SFB 230-Natürliche Konstruktionen, Leichtbau in Architektur und Natur" at the universities in Stuttgart and Tübingen. Indeed, hardly an ill word is said of Thompson, except for his sometimes being accused of being too much of a structuralist.

In the design world, Thompson's theories could be incorporated into those of either 'sentient engineering design' or genetic algorithms, or could stand alone on their own. To design a shell, we analyze how the loads shape the shell. However, the designer who does not incorporate the structural behavior of the object is just imitating nature for its looks, and thus doing what Loos argued against: consciously trying to make the structure beautiful.

We are sure that Thompson would say that we should try to understand how nature has "solved" technological problems and that only when we have this 
understanding should we try and apply it ourselves. Unfortunately in architecture this is not always the case. We see structures that copy nature's looks while ignoring how they came to be. For example, Zaha Hadid's London Aquatics Center was inspired "by the fluid geometry of water in motion ... An undulating roof sweeps up from the ground as a wave" (Crockford et al. 2011: 45). A building is a static structure; a wave comes crashing down.

There is a real danger in imitating nature's aesthetics for beauty alone while ignoring the fact that the form is clearly shaped by the physical laws of nature. Part of nature's beauty is that it makes sense and is expressive. Those are some of the attributes we outlined earlier that we find beautiful about shells.

Le Corbusier was influenced by Thompson and nature as well as machines. Figure 24 in Corbusier's Aircraft: L'Avion accuse ... (1935) is identified as a 'Master Connecting Rod and other parts of a Bristol "Pegasus" engine'; he remarks about this image, '[t]here are no "details". Everything is an essential part of the whole. In nature microcosm and macrocosm are one' [1935: not numbered (33)], thus linking the aesthetics and functionality of engineering to those of nature, and echoing Adolf Loos. Le Corbusier was a contemporary of and interacted with Einstein and Picasso, reminding us of a time when people genuinely felt that there was an overarching connection between science, art and architecture.

Our objective here is to encourage engineers to be able to talk about aesthetics and to share some thoughts on the topic; this is why we proposed a special issue of the NNJ to examine the aesthetics, structure and mathematics of shell and tensile structures. Let us now introduce the contributions to this issue.

This issue opens with 'From Shells to Tensile Structures: A Personal History', in which world-renowned engineer Matthys Levy shares his experiences over a career of seven decades with shells and tensile structures.

In 'The Lightfall and the Symbolic Function of the Hyperbolic Paraboloid Surface', Eran Neuman argues that while the hyperbolic paraboloid surface has carried significance beyond the structural and mathematical realm, its lightfall goes beyond its shape and form and beyond its mathematical idea.

Emanuel Jannasch, in 'Fit Forms and Free Forms of the Masonry Dome', challenges our notions of what is beautiful and our assumption that natural solutions are inherently beautiful by exploring counter-intuitive forms.

In 'The Equilibrium of Corrugated Plates and Shells', we guest editors, Samar Malek and Chris Williams, derive a closed form solution for corrugated shells that can be used to compare analytical and numerical solutions.

In 'Integrated Design Approach for Shell Structures Using Isogeometric Analysis' Philipp Längst, Alexander Michalski and Julian Lienhard demonstrate a method to integrate the design and analysis of shells using isogeometric analysis, that is, the mathematical description of geometry with NURBS within an analysis based on finite elements.

Rizal Muslimin, in 'On Visual-Mechanical Synthesis in Shell Structures', develops a computational method for shell design that uses the interplay between mechanical idealization and visual computation using traditional craft as a reference. 
Jorge Galindo Díaz and Hernando Vargas Caicedo present 'Geometry and Construction at Cartagena de Indias Baseball Stadium's Thin Shell Roofs (Colombia 1947)', which are the works of Colombian engineer Guillermo González Zuleta.

In 'Dante Bini's Form-Resistant Binishells' Alberto Pugnale and Alberto Bologna review the career and creations of Italian engineer Dante Bini.

Leonardo Todisco, Giuseppe Sanitate and Giuseppe Lacorte provide a review of 'trulli', a dried stone vernacular structure, and their building typology and construction technique, in 'Geometry and Proportions of the Traditional Trulli of Alberobello'.

Francesco Gherardini and Francesco Leali provide a review of reciprocal frames and conduct a parametric and aesthetical investigation of them.

In 'Laminar Constructions and Reciprocal Structures' Javier Barrallo, Francisco González-Quintal, and Antonio Sánchez-Parandiet present reciprocal frames built from thin sheets instead of linear members, thus allowing for a curved surface.

Finally, no work on the aesthetics of shell structures could be complete without a detailed discussion of the work of Heinz Isler. The paper 'Rooted in Nature: Aesthetics, Geometry and Structure in the Shells of Heinz Isler' by John Chilton and Chu-Chun Chuang discusses Isler's work in relation to that of Torroja, Nervi and Candela. It gives a detailed description of Isler's design process for the Sicli Pavilion and compares it to what might be done today using digital tools.

There is no simple answer as to where beauty lies, but when it comes to shells we strongly believe that beauty is found in the synergy between structures, aesthetics and mathematics. We would like to conclude with a quote from the section entitled 'Rationality and Expressiveness' in Eladio Dieste's article "Some Reflections on Architecture and Construction".

In many cases structures have the ability to move us and attract us because they are mysteriously expressive. Our excitement is primarily due to the fact that we perceive these structures not only with our eyes but with our spirit, and they display a more adaption to the laws that control matter in equilibrium.... Giving form to a work, consciously or unconsciously, is like leaping into a void and we want that jump to be more a flight than a fall. This is why it is more accurate to speak of an art of building than of a science of building. But we must remember that there is no art without science, and that it will take much rational effort to acquire the ability to take that jump (Dieste 1992: 193).

Acknowledgements We would like to thank all the authors for their contributions. We especially thank Co-Editors-in-Chief Kim Williams and Professor Michael Ostwald for their guidance and their continued work for this journal.

\section{References}

Bricmont, Jean and Alan Sokal. 1998. Intellectual Imposters. London: Profile.

Crockford, Ian, Malcolm Nelson, Stuart Fraser, Gordon Mungal and John Nicholson. 2011. Delivering London 2012: The Aquatics Centre. Proceedings of the Institution of Civil Engineers - Civil Engineering 164(6): 44-50. 
Darwin, Charles. 1859. On the Origin of Species by Means of Natural Selection. London: John Murray. Deleuze, Gilles. 1993. The Fold: Leibniz and the Baroque. London: Athlone Press.

Dieste, Eladio. 1992. Some reflections on architecture and construction. Perspecta 27:187-203.

Dirac, P.A.M. 1975. General Theory of Relativity. New York: Wiley.

Eco, Umberto. 1988. The Aesthetics of Thomas Aquinas. Cambridge, MA: Harvard University Press.

Eco, Umberto. 2010. On Beauty: A History of a Western Idea. London: MacLehose Press.

Green, A. E. and W. Zerna. 1968. Theoretical Elasticity. Oxford: Oxford University Press.

Koiter, W. T. 1970. On the Mathematical Foundation of Shell Theory. In Actes du congrs international des mathmaticiens, 123-130.

Le Corbusier. 1935. Aircraft: L'Avion accuse.... Paris: Biro. Eng. trans. Aircraft: The New Vision, London: The Studio, 1935.

Loos, Adolf. 1975. Architecture (1910). Rpt. in Architecture and Design 1890-1939, Tim Benton and Charlotte Benton, eds., 41ff. New York: Whitney Library of Design, 1975.

Malek, Samar and Williams, Chris. The equilibrium of corrugated plates and shells. Nexus Network Journal, Jul 2017.

Maxwell, J. Clerk. 1870. On Reciprocal Figures, Frames, and Diagrams of Forces. Transactions of the Royal Society of Edinburgh 26(1):1-40.

Naghdi, Paul M. 1962. Foundations of Elastic Shell Theory. Los Angeles: Institute of Engineering Research, University of California.

Pettigrew, James Bell. 1908. Design in Nature, Vol.1. London: Longmans, Green \& Co.

Scruton, Roger. 2011. A Bit of Help from Wittgenstein. The British Journal of Aesthetics 51(3): 309-319.

Sokal, Alan D. 1996. Transgressing the Boundaries: Toward a Transformative Hermeneutics of Quantum Gravity. Social Text 46/47: 217-252.

Struik, Dirk. J. 1961. Lectures on Classical Differential Geometry. Boston: Addison-Wesley Publishing Co.

Thompson, D’Arcy Wentworth. 1917. On Growth and Form. Cambridge: Cambridge University Press. Timoshenko, S. 1961. Theory of Elastic Stability. New York: McGraw-Hill.

Varignon, Pierre. 1725. Nouvelle mécanique ou statique. Paris: Claude Jombert.

Wittgenstein, Ludwig. 1922. Tractatus Logico-Philosophicus. C. K. Ogden, trans. London: Kegan Paul. Rpt. New York: Dover, 1999.

Samar Malek, United States Naval Academy, is a structural engineer with expertise in structural and computational mechanics, and gridshells. She completed her Ph.D. and S.M. in Structures and Materials at MIT where she was also a lecturer in the Department of Architecture. Dr. Malek is a Marshall-Sherfield Scholar and completed her post-doctorate at the University of Bath Department of Architecture and Civil Engineering. She has practiced as a structural engineer at Thornton Tomasetti, NYC, and consulted on gridshell projects for Atelier One, London. Her research interests include computational methods in conceptual structural design, gridshells, deployable shelters and biomimicry in architecture and engineering.

Chris J. K. Williams, Chalmers University and Bath University, worked with Ted Happold and Ian Liddell at Ove Arup and Partners on the Frei Otto gridshells in Mannheim. This led to his research interest in the relationship between geometry and structural action, and collaboration on a number of projects, including the British Museum Great Court Roof (Buro Happold and Foster + Partners), the Savill Building (Buro Happold and Glenn Howells Architects), Gardens by the Bay glasshouses (Atelier One, Wilkinson Eyre and Grant Associates) and the Netherlands Maritime Museum (Ney + Partners). 